\title{
CRIATIVIDADE, PSYCAP E LIDERANÇA: A VISÃO DOS PROFISSIONAIS DAS ORGANIZAÇÕES DE SAÚDE
}

\author{
Fernanda Nogueira ${ }^{1}$ \\ Carla Marques $^{2}$ \\ Ana Sabino 3 \\ Ivo Oliveira ${ }^{4}$ \\ Carlos Rouco ${ }^{5}$ \\ Ana Branca Carvalho ${ }^{6}$
}

\begin{abstract}
Resumo: Nas organizações do sector de saúde, a pesquisa sobre liderança e o seu impacto no capital psicológico e na criatividade, em qualquer tipo de contexto organizacional, é quase inexistente. Para reduzir essa lacuna, o objetivo deste texto foi identificar em que medida a percepção de uma liderança autêntica $e$ o capital psicológico influenciam a criatividade dos profissionais de um Centro Hospitalar Português. Os dados relacionados com os conceitos de liderança, capital psicológico e criatividade foram obtidos por meio de um questionário constituído por três partes: capital psicológico positivo; liderança autêntica, e dados demográficos e funcionais, numa amostra de 61 líderes das chefias intermédias dos diversos serviços dos 22 departamentos de Centro Hospitalar, bem como de 183 colaboradores selecionados aleatoriamente pelos líderes. As respostas foram analisadas através da utilização das análises fatoriais e das equações estruturais. Os resultados obtidos confirmaram duas das três hipóteses consideradas no estudo, sugerindo a existência de uma forte relação entre a liderança autêntica e o capital psicológico, $e$ entre este e a criatividade, não sendo explicada diretamente a criatividade pela liderança. Concluiu-se ainda que a liderança e o
\end{abstract}

\footnotetext{
${ }^{1}$ ISCSP - Universidade de Lisboa, CAPP (fnogueira@iscsp.ulisboa.pt)

${ }^{2}$ DESG, Universidade de Trás-os-Montes e Alto Douro, CETRAD

(smarques@utad.pt)

${ }^{3}$ ISCSP - Universidade de Lisboa, CAPP (ana.margarida.sabino@ gmail.com)

${ }^{4}$ ISLA - Instituto Politécnico de Gestão e Tecnologia, CEPESE

(ivodinisoliveira@gmail.com)

${ }^{5}$ Academia Militar, CINAMIL (carlos.rouco@academiamilitar.pt)

${ }^{6}$ ESTGL - Instituto Politécnico de Viseu, CIDETS - (acarvalho@estgl.ipv.pt)
} 


\title{
Fernanda Nogueira, Carla Marques, Ana Sabino, Ivo Oliveira, Carlos Rouco e Ana Branca Carvalho
}

capital psicológico têm, nas organizações de saúde, uma forte relação com a criatividade dos seus profissionais.

Palavras-chave: Liderança Autêntica, Capital Psicológico e Criatividade

\section{Title: CREATIVITY, PSYCAP AND LEADERSHIP: THE SIGHT OF PROFESSIONALS IN HEALTH ORGANIZATIONS}

\begin{abstract}
Research on authentic leadership and its impact on employees' psychological capital and creativity is almost non-existent In the health sector. To reduce this gap, this paper aims to identify to what extent the perception of authentic leadership and psychological capital influence the creativity of professionals in a large Portuguese hospital. Data were collected on the key concepts of authentic leadership, psychological capital and creativity. via a three-part questionnaire focusing respectively on positive authentic leadership, psychological capital, and demographic and functional data, which was administered to a sample of 61 middle managers in the various hospital services. 22 departments and 183 randomly-selected other employees. Fatorial analysis and structural equation modelling were used to process the results. The results confirmed two of the three hypotheses considered in the study, indicating that while a strong relationship existed both between authentic leadership and psychological capital, and between the latter and creativity, authentic leadership did not directly explain creativity. Our conclusion is that, in organizations providing health services, authentic leadership and psychological capital are phenomena that are interrelated in that they influence professionals' creativity.
\end{abstract}

Key Words: Authentic Leadership, Psychological Capital and Creativity

\section{INTRODUCÃO}

No início do século XXI, assiste-se a mudanças significativas a nível mundial, reflexo do desenvolvimento tecnológico e científico que impulsiona o conhecido fenómeno da globalização. Globalização de ideias e mudanças aceleradas que acarretam, constantemente, a reorganização e a reformulação das estruturas tradicionais de gestão e liderança, que seriam eficazes para o sucesso das organizações, mas que cada vez mais se desmoronam face à competição global. As organizações, em geral, vivem em sociedades abertas e complexas (Ceitil, 2006; Friedman, 2005), que buscam ultrapassar desafios e responder, em tempo real, às sucessivas 
mudanças na tentativa de se tornarem mais eficientes e competitivas (Piderit, 2000; Graetz; Smith, 2009).

No debate sobre mudança e desenvolvimento organizacional, surge a liderança como agente facilitador da implementação de novos processos organizacionais, sendo a tónica colocada na promoção do Capital Humano nas organizações. Espera-se dos colaboradores alto desempenho, criatividade, inovação e envolvimento para que se concretizem os processos de mudança organizacional de forma célere e eficaz. Esse pensamento leva à análise da relação dos indivíduos para com as organizações, principalmente no que concerne à participação, ao compromisso e à adesão dos mesmos com vista ao alcance de um determinado projeto organizacional. Nas organizações, as pessoas são avaliadas não por esquemas operacionais predefinidos, redutíveis a uma mera descrição de funções, mas pelas sínteses cognitivas que cada um realiza no seu exercício, moldando o trabalho em função da sua inteligência, tanto cognitiva como emocional, e das suas motivações e competências (George, 2003; Ceitil, 2006). O capital humano passa a ser considerado um elemento gerador de valor nas organizações como um todo.

Nesta linha, torna-se fundamental questionar que líderes e que lideranças podem dar resposta aos desafios provenientes do desenvolvimento e da mudança permanente das organizações. São vários os pesquisadores, entre eles Bunker e Wakefield (2005) e Hooper e Potter (2010), que direcionam a atenção para a liderança e o que ela causa nas atitudes e comportamentos dos colaboradores e, consequentemente, no desenvolvimento das organizações. Estes autores afirmam que liderar é envolver, guiar, orientar por meio do exemplo, criar condições que promovam o desenvolvimento da capacidade criativa tanto em âmbito individual como institucional, é usar o poder para conferir poderes e liberdade aos outros no sentido da criatividade e, por conseguinte, do desenvolvimento organizacional.

No cenário de mudança, reorganização, readaptação organizacional, voltado para o desenvolvimento, as organizações do sector da saúde parecem estar longe do preconizado, havendo muito caminho a percorrer e, possivelmente, lideranças autênticas genuínas por incrementar. Nestas organizações, a linha de pesquisa sobre liderança autêntica e o seu impacto no capital psicológico e na criatividade dos colaboradores, nos mais diversos contextos, é quase inexplorada. É precisamente para 


\section{Fernanda Nogueira, Carla Marques, Ana Sabino, Ivo Oliveira, Carlos Rouco e Ana Branca Carvalho}

ultrapassar este hiato que se posiciona o estudo aqui apresentado, pretendendo contribuir para um melhor conhecimento do efeito que a liderança e o capital psicológico têm no comportamento criativo dos profissionais num Centro Hospitalar Português.

Assim, com base na questão central deste artigo - em que medida a liderança autêntica e o capital psicológico influenciam a criatividade dos profissionais do sector da saúde - serão, a seguir, apresentados os conceitos de liderança, de capital psicológico e de criatividade, essenciais ao entendimento do modelo conceptual utilizado.

\section{ESTRUTURA CONCEPTUAL: SOBRE A LIDERANÇA, O CAPITAL PSICOLÓGOCO E A CRIATIVIDADE}

\subsection{Liderança}

A Liderança, diz George (2009), começa e termina com a autenticidade, sendo o líder coerente com os seus valores, com a sua forma de ser e de estar. A esse propósito, Maxwell (2010) afirma serem os líderes eficazes por causa do que são interiormente, das qualidades que os definem como pessoas. Ao assumir um estilo de liderança autêntico, o líder não nega os sentimentos e as emoções que experimenta, expressa-os abertamente, conseguindo relacionar-se com os outros de forma real, genuína, ou seja, autêntica. A autenticidade favorece qualquer situação cujo objetivo vise a convivência harmoniosa e o desenvolvimento pleno das potencialidades das pessoas. Na definição de líderes autênticos, segundo autores como Kernis (2003), Avolio et al.(2004) e Vitória (2010), são utilizados adjetivos como carácter, harmonia, honestidade, sinceridade, integridade, transparência, real, verdadeiro, genuíno, completo, entre outros.

Segundo a perspetiva de Goleman et al. (2007), os líderes são pessoas que mobilizam outras pessoas, acendem paixões e inspiram o que de melhor existe, funcionando como guias emocionais dos grupos, influenciando as emoções coletivas em direções positivas. As emoções direcionadas para o entusiasmo desses líderes conseguem o melhor das pessoas, aperfeiçoando os seus desempenhos, mas, se, pelo contrário, forem encaminhadas para estados afetivos negativos, os seguidores podem ficar desorientados e até mesmo paralisados. Neste último caso, os líderes não são capazes de proporcionar ambientes de trabalho onde reine a confiança, o bem-estar e a percepção de justiça (Goleman et al., 2002). 
Fredrickson (2003) ressalta que as emoções positivas do líder podem ser particularmente contagiosas, fomentando transformações no desenvolvimento organizacional.

Por sua vez, Luthans e Avolio (2003), Avolio et al. (2004), Mayer e Gavin (2005) e Gardner et al. (2005) referem que os líderes autênticos, além de possuírem perspetiva ética e moral, estão orientados para o futuro e dão prioridade ao desenvolvimento e à criatividade dos seus seguidores. Esses líderes consideram as pessoas otimistas, confiantes, esperançosas e resilientes, verdadeiros com eles próprios e consonantes nas ações, tendo a capacidade de influenciar positivamente os seus seguidores. Por outro lado, Cunha e Rego (2009), Cunha, Rego e Cunha (2007) afirmam que, entre as principais caraterísticas e ações dos líderes positivos e eficazes, está a de sublinhar a promoção de um clima organizacional, no qual as pessoas têm consideração pela sua opinião e que, por isso, promovem a confiança, encorajam a criatividade e fomentam a abertura à mudança. Em síntese, investigadores, como Avolio, George, Luthans, Walumbwa, Kernis, Gardner e Weber, entre outros, têm estudado a liderança autêntica e de que forma é que, esta, está associada a melhores índices de desempenho, satisfação no trabalho e desenvolvimento organizacional.

Walumbwa et al. $(2008,2010)$ desenvolveram um instrumento de medida com quatro dimensões da liderança autêntica tendo por base a interação entre um padrão de comportamento do líder, que fomenta as capacidades psicológicas positivas e, consequentemente, um clima organizacional positivo, assentes num código de ética onde a autoconsciência (consciência das suas próprias forças e fraquezas), a perspetiva moral integrada (elevados padrões éticos e ações concordantes), a transparência relacional (abertura e aceitação) e o processamento equilibrado (decisões baseadas na escuta atenta) são considerados constructos nucleares deste estilo de liderança.

Dando continuidade à apresentação dos conceitos aqui estudados, segue-se o de capital psicológico por ser considerado fundamental para a geração de valores nas organizações.

\subsection{Capital Psicológico}

As organizações dependem, no seu dia a dia, dos contributos e das iniciativas individuais para passar da identificação de problemas à resolução dos mesmos. Para tal, necessitam de recorrer à reserva de conhecimentos e às experiências de que dispõem os seus colaboradores 


\section{Fernanda Nogueira, Carla Marques, Ana Sabino, Ivo Oliveira, Carlos Rouco e Ana Branca Carvalho}

(Blanchard, 2009), ativo intangível que pode ser desenvolvido e reforçado tornando-se numa vantagem competitiva para a organização. $\mathrm{O}$ conceito de capital psicológico refere-se à aplicação dessas forças orientadas para os pontos fortes e para as capacidades psicológicas dos seres humanos, que podem ser medidas, desenvolvidas e eficazmente geridas para melhorar o desempenho individual e profissional (Luthans, 2002a; Luthans, 2002b; Luthans \& Youssef, 2007; Luthans \& Youssef; Avolio, 2007; Mayer \& Gavin, 2005). Assim, o capital psicológico (PsyCap) pode ser definido como um estado psicológico individual e de desenvolvimento, caraterizado por autoeficácia, esperança, otimismo e resiliência (Luthans; Avolio, 2003; Luthans \& Youssef, 2004; Shamir \& Eilam, 2005; Luthans, Avolio, Avey et al., 2007; George, 2009; Rego \& Cunha, 2010). Estas quatro características - autoeficácia, esperança, otimismo e resiliência constituem a base nuclear do capital psicológico e podem alterar o desempenho da organização.

A gestão do capital psicológico canaliza forças e capacidades que se traduzem em resultados éticos, proveitosos, sustentáveis, que resultam em vantagem competitiva. Os autores supracitados explicam, ainda, que as pessoas que possuem uma combinação dessas quatro características acreditam que podem enfrentar tarefas difíceis (autoeficácia) e que situações desafiadoras terão uma solução favorável (otimismo), são perseverantes e mudam de direção para alcançar os seus objetivos (esperança), sendo capazes de tentar novamente e obter sucesso mesmo diante da adversidade (resiliência) (Lyubomirsky, 2008). Desta forma, a inteligência ou o especial talento dos colaboradores, possivelmente, não serão os únicos determinantes do diferencial competitivo de uma organização, mas sim o capital psicológico, presente nas pessoas comuns, que lhes vai permitir enfrentar as adversidades, vencer obstáculos, manter o vigor e encarar o futuro como repleto de oportunidades. As organizações, através dos seus líderes, considerando o capital psicológico, promovem e estimulam essas dimensões nos seus seguidores, criando capital dificilmente imitável por outras organizações, tornando-as mais competitivas e eficientes, o que pode levar à seguinte hipótese: $\mathbf{H 1}$ - A percepção de uma liderança autêntica relaciona-se positivamente com o capital psicológico (PsyCap) dos colaboradores. Luthans, Youssef e Avolio (2007) e Rego e Cunha (2010), ressaltam ainda como consequente potencial do capital psicológico outras características, entre elas a criatividade, levando-nos de seguida a refletir sobre o mesmo. 


\subsection{Criatividade}

Conceitos como a criatividade e a inovação surgem como elementos críticos de sucesso para as organizações (Amabile, 1988; Oldham \& Cummings, 1996; Zhou \& Shalley, 2003; Zhou \& Ren, 2012), estando na sua base as ideias que, muitas vezes, nesses ambientes, não são valorizadas. Criatividade, é ter uma ideia original, é encontrar outra maneira de fazer a mesma coisa. Sternberg (1988) e Sternberg e Lubart (1991), com a teoria do investimento em criatividade, Amabile (1983, 1989, 1996) com o modelo componencial da criatividade e Csikszentmihalyi $(1988,1996,2003)$ e a perspetiva dos sistemas, atribuem a produção criativa a um conjunto de fatores que interagem de forma complexa e que dizem respeito tanto ao indivíduo quanto às variáveis sociais, culturais e do ambiente em que este está inserido (Alencar \& Fleith, 2003). Também nas organizações a criatividade é o resultado da interação entre os pensamentos do criador (habilidades cognitivas, traços de personalidade) e o contexto sociocultural (aspectos facilitadores e inibidores) em que esta está inserida (Csikszentmihalyi, 1996, 2003). Segundo Oldham e Cummings (1996), o desempenho criativo dos colaboradores fornece a matéria-prima necessária à inovação organizacional. Colaboradores criativos são recursos que, além de serem suscetíveis de oferecer ideias criativas para a resolução de problemas, promovem outras ideias diferentes para o desempenho de diferentes funções (Shalley \& Gibson, 2004).

House (2003) afirma que a falta de criatividade é uma ameaça à competitividade das organizações refletindo-se na economia global, uma vez que a criatividade representa um modo de responder mais eficazmente à resolução dos problemas. Zhou e George (2003) defendem que os líderes influenciam a criatividade dos seus colaboradores: (1) diretamente, por meio de comportamentos de incentivos e encorajamento e, ainda, assumindo e propondo novas ideias e (2) indiretamente por meio da criação de ambientes de trabalho facilitadores da criatividade (Zhou \& George, 2003; George \& Zhou, 2007; Wang \& Cheng, 2010; Zhang \& Bartol, 2010). Cada vez mais, fica claro que a criatividade dos colaboradores é uma peça fundamental para que se atinja a excelência no desempenho organizacional, sendo considerada uma dimensão expressa, ou latente, nas organizações podendo, ou não, ser posta em prática e ao serviço dos objetivos organizacionais. Cabe, assim, aos líderes fomentá-la e criar contextos que a facilitem (Ilies et al., 2005). Avolio et al. (2004, 


\section{Fernanda Nogueira, Carla Marques, Ana Sabino, Ivo Oliveira, Carlos Rouco e Ana Branca Carvalho}

2005) sugerem que líderes autênticos, ao estabelecerem relações de qualidade com os seus seguidores, influenciam positivamente os seus comportamento promovendo bem-estar, o que contribui para melhorar o seu desempenho. Desta forma, é estimulada a autodeterminação, a segurança e a confiança dos colaboradores preparando-os para que focalizem as suas energias criativas nos objetivos e encontrem diferentes caminhos para resolver problemas, aproveitando as oportunidades que surgem (Avolio et al., 2004; Ilies et al., 2005; Sousa; Monteiro, 2010). É neste contexto que nos surge a hipótese três deste estudo: H3 - A percepção da liderança autêntica relaciona-se positivamente com a criatividade dos colaboradores.

Os colaboradores, por seu lado, observam o comportamento dos líderes autênticos o que os leva à motivação intrínseca no trabalho, aumentando os seus níveis de autoeficácia/confiança e criatividade (Csikszentmihalyi, 2003; Gardner et al., 2005; Luthans et al., 2006; Shamir \& Eilam, 2005). Por outro lado, as evidências disponíveis indicam que as consequências cognitivas dos afetos sendo muitas e diversificadas (a flexibilidade cognitiva, a atenção demonstrada ou as estratégias de pensamento), podem criar indivíduos com um estado de espírito capazes de gerar mais ideias e identificar um maior leque de alternativas de resolução ou criação (James, Brodersen \& Eisenberg, 2004). Foi com base nestes pressupostos que formulamos a segunda hipótese do estudo: H2 - O capital psicológico (PsyCap) dos colaboradores relaciona-se positivamente com a sua criatividade.

Em síntese, parece ser consensual afirmar que colaboradores criativos produzem ideias inovadoras no nível dos produtos, das práticas e dos procedimentos organizacionais. Torna-se, assim, relevante indagar em que medida a liderança, em instituições peculiares como as hospitalares, propicia a formação desse tipo de colaborador criativo. Ou, ainda, até que ponto estas instituições se tornam ambientes propícios à inovação e aumentam o seu desempenho, com a atuação de uma liderança autêntica que estimula a criatividade dos profissionais. Refere Frederico (2006) que os Hospitais se enquadram nas organizações mais complexas da sociedade moderna, sendo organizações de elevada diferenciação, constituídas por meios tecnológicos e humanos altamente especializados, com o propósito de prestarem cuidados de saúde durante 24 horas por dia, 365 dias por ano. São organizações com um amplo e rigoroso leque de aptidões técnicas e desenvolvem as suas atividades num sistema composto por 
múltiplos agentes de natureza, nível e características diferentes, interatuando com praticamente todas as expressões do tecido social e da sociedade (Schyve, 2009). Um dos problemas mais graves de gestão no Serviço Nacional de Saúde (SNS), lembra Carvalho (2008), decorre da falta de coesão, clarificação, identificação e assunção solidária entre os diferentes grupos de poder e liderança. As evidências empíricas analisadas por este autor indicam que o foco do problema do SNS reside nas competências de gestão do nível político-administrativo das organizações e das suas unidades estratégicas. Face a este diagnóstico, parece ser urgente a alteração dos processo de liderança, os quais, na opinião de Carvalho (2008, p.93), só serão atingíveis se forem processados "por dentro, para dentro e com os de dentro das respectivas estruturas, no sentido de que as unidades nucleares do sistema sejam a base, o sustento e o efetivo núcleo de desenvolvimento das organizações hospitalares". Conjuntamente e face às necessidades das reformas no SNS, não só pela emergente sustentabilidade do sistema como, também, pela melhoria da qualidade do seu desempenho por meio da satisfação dos profissionais e utilizadores, parece que as sucessivas mudanças têm contribuído para diminuir a credibilidade do sistema junto aos cidadãos, profissionais de saúde e utilizadores dos serviços de saúde.

As três hipóteses formuladas anteriormente levam-nos a elaborar o modelo conceptual de pesquisa, Figura I, através do qual se procura responder à questão: em que medida a percepção de uma liderança autêntica e do capital psicológico influenciam o comportamento criativo dos profissionais de Saúde?

Figura I

Modelo Conceitual de pesquisa

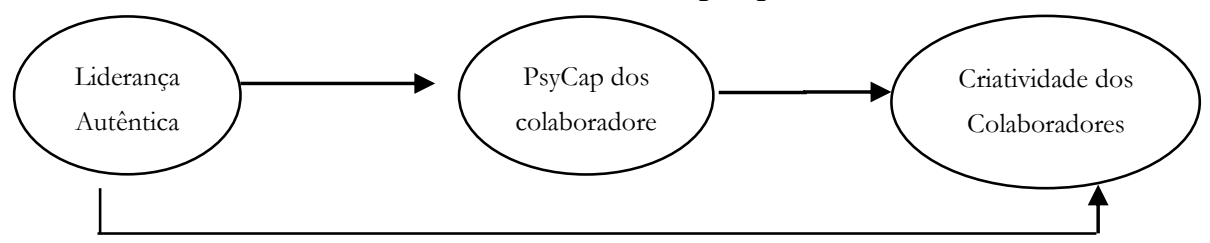




\section{Fernanda Nogueira, Carla Marques, Ana Sabino, Ivo Oliveira, Carlos Rouco e Ana Branca Carvalho}

\section{MÉTODO}

Face ao objetivo proposto, a seleção da amostra recaiu sobre duas populações distintas, constituídas por um líder e por três colaboradores da sua equipe, dos diversos departamentos e diferentes grupos de trabalho que compõem o Centro Hospitalar de Trás-os-Montes e Alto Douro E.P.E.. O Centro integra o Hospital Distrital de Vila Real/Peso da Régua, E.P.E., o Hospital Distrital de Chaves, o Hospital Distrital de Lamego e a Unidade de Cuidados Continuados de Vila Pouca de Aguiar com as valências de Cuidados Continuados de Convalescença e Cuidados Continuados Paliativos. O Centro é parte integrante do Serviço Nacional de Saúde (SNS) Português sendo a sua área de influência de 452.000 habitantes e de 34 concelhos. O quadro de pessoal apresentava, em 2009, um registo de 2.321 colaboradores, concentrando-se o maior número $(61,6 \%)$ em Vila Real e na Régua, enquanto que, em Chaves e Lamego, a concentração era de $24,5 \%$ e $13,9 \%$ respectivamente ${ }^{7}$.

A amostra foi selecionada nas chefias intermédias dos diversos serviços que constituem os 22 departamentos do Centro Hospitalar, por duas vias: líderes e colaboradores. Aos 61 líderes selecionados foi solicitada a descrição dos níveis de criatividade de seus três colaboradores selecionados aleatoriamente. Aos 183 colaboradores descritos, avaliados pelos líderes, foi solicitado que respondessem a um questionário constituído por três partes: níveis de capital psicológico; níveis de liderança autêntica dos seus líderes e, a terceira, dados demográficos e funcionais. Após o preenchimento, todos os questionários foram colocados em envelopes para salvaguardar o anonimato, sendo-lhes atribuído um código alfanumérico. Por último, foram agrupados os 4 questionários com o mesmo número de código (do líder e dos 3 colaboradores) para fazer corresponder as respostas dos líderes às dos seus colaboradores. Apenas um líder de departamento se recusou a participar, alegando falta de receptividade dos seus colaboradores diretos e não concordar com pesquisas desenvolvidas por questionários.

A percepção da liderança autêntica foi medida pela versão portuguesa de Sousa (2009) do instrumento criado e validado por Walumbwa et al. (2009), composto de 16 itens e uma escala de Likert de cinco pontos distribuídos de 1, Nunca, a 5, Habitualmente, na qual é solicitado aos líderes e colaboradores a indicação, face às suas percepções, em que

\footnotetext{
${ }^{7}$ Versão eletrónica do Relatório e Contas do CHTMAD, de 2009.
} 
posição se sentem confortáveis perante as afirmações. O instrumento mede as quatro dimensões da liderança autêntica: transparência relacional (cinco afirmações), perspetiva moral integrada (quatro afirmações), processamento equilibrado (três afirmações) e autoconsciência (quatro afirmações).

O capital psicológico dos colaboradores foi medido por um questionário específico para o contexto organizacional, versão portuguesa de Rego et al. (2012), desenvolvido e validado por Luthans, Youssef e Avolio (2007), constituído por 24 itens, numa escala de Likert de cinco pontos variando de 1 - A afirmação não se aplica a mim a 5 - A afirmação aplica-se a mim. $\mathrm{O}$ instrumento mede as quatro dimensões do capital psicológico: autoeficácia (seis afirmações), otimismo (seis afirmações), esperança (seis afirmações), e resiliência (seis afirmações).

A criatividade dos colaboradores foi medida pela versão portuguesa de Rego et al. (2007) do questionário adaptado e validado por Zhou e George (2001), que acrescentaram 3 itens ao questionário criado por Scott e Bruce (1994). O instrumento, constituído por afirmações a serem associadas pelos líderes aos colaboradores, possui 13 itens, numa escala de Likert de cinco pontos indo de 1 - Nunca a 5 - Habitualmente.

A opção por este método deve-se à menor exigência em termos de tempo, recursos financeiros e recursos humanos, além de apresentar segurança e rigor pelo fato de as respostas serem anónimas e não terem qualquer intervenção por parte do investigador (Barañano, 2004; Lakatos \& Marconi, 2007). A distribuição dos questionários decorreu entre os meses de julho e setembro de 2010. Dos líderes inquiridos 53,6\% são do sexo masculino, 44,6\% do sexo feminino, e 1,8\% não responderam. A média etária é de 49 anos (DP=4,739), estando a maioria dos líderes entre os 46 e 55 anos de idade. A antiguidade média de permanência na instituição é de 23,7 anos ( $\mathrm{DP}=5,247)$, sendo o nível de escolaridade maioritário $(76,78 \%)$ o ensino superior completo. Na amostra dos colaboradores a maioria são profissionais de enfermagem (76,8\%), sendo $78,6 \%$ do sexo feminino, com uma média etária de 40 anos (DP=9,091). A antiguidade média de permanência na instituição é de 13,63 anos $(\mathrm{DP}=8,507)$. Todos os resultados que apresentamos de seguida foram apurados recorrendo ao programa informático IBM SPSS 19.0 e IBM AMOS 19, efetuando análises fatoriais e equações estruturais. 


\section{Fernanda Nogueira, Carla Marques, Ana Sabino, Ivo Oliveira, Carlos Rouco e Ana Branca Carvalho}

\section{RESULTADOS DA ANÁLISE FATORIAL}

\subsection{Confiabilidade e Validade dos Instrumentos de Medida}

A validade fatorial do modelo que visa descrever os níveis de liderança autêntica (LA), segundo os respectivos colaboradores, o capital psicológico dos colaboradores e a criatividade dos mesmos, foram avaliados por intermédio de análises fatoriais confirmatórias de acordo com Maroco (2010). Foram avaliadas a confiabilidade compósita e a variância extraída média por fator, conforme Fornell e Larcker (1981), a existência de outliers pela distância quadrada de Mahalanobis (DM2) e a normalidade das variáveis pelos coeficientes de assimetria (sk) e curtose (ku) uni- e multivariada. Nenhuma variável apresentou valores de Sk e Ku indicadores de violações severas à distribuição Normal - $|\mathrm{Sk}|<3$ e $|\mathrm{Ku}|<10$ (Maroco, 2010). A qualidade de ajustamento global do modelo fatorial foi feita de acordo com os índices e respectivos valores de $\chi 2 / g l$, CFI, GFI, PCFI, PGFI, RMSEA, P[rmsea $\leq 0.05]$ e MECVI. A qualidade do ajustamento local foi avaliada pelos pesos fatoriais e pela fiabilidade individual dos itens. O refinamento do modelo foi efetuado com base nos valores dos índices de modificação pelos multiplicadores de Lagrange (LM), produzidos pelo AMOS, considerando-se que trajetórias e/ou correlações com LM>11 $(\mathrm{p}<0.001)$ são indicadores de variação significativa da qualidade do modelo.

\subsection{Liderança Autêntica}

O modelo tetrafatorial da Liderança Autêntica original, ajustado a uma amostra de 163 colaboradores revelou uma boa qualidade de ajustamento $(\chi 2 / \mathrm{gl}=1.855 ; \quad$ CFI $=0.957 ; \quad$ GFI $=0.884 ; \quad$ PCFI $=0.781 ; \quad$ PGFI $=0.637 ;$ RMSEA $=0.072 ; \quad \mathrm{P}[\mathrm{rmsea} \leq 0.05]=0.017 ; \quad \mathrm{MECVI}=1.595)$. Depois $\mathrm{de}$ eliminadas quatro observações outliers, foi possível melhorar ligeiramente a qualidade de ajustamento $(\chi 2 / \mathrm{gl}=1.750 ; \mathrm{CFI}=0.964 ; \mathrm{GFI}=0.886$; PCFI $=0.787 ; \quad$ PGFI $=0.638 ; \quad$ RMSEA $=0.068 ; \quad \mathrm{P}[\mathrm{rmsea} \leq 0.05]=0.044 ;$ MECVI=1.573). Adicionalmente, o modelo sem os outliers apresentou uma qualidade de ajustamento superior à do modelo original na amostra sob estudo $(\mathrm{X} 2(98)=171.522$ vs. $\mathrm{X} 2(98)=181.821)$, bem como um MECVI menor (1.573 vs. 1.595). A confiabilidade compósita dos fatores (FC) revelou-se elevada pelo que a confiabilidade do construto é adequada (FC $\geq 0.7)$. A variância extraída média (VEM), um indicador da validade 
convergente dos fatores, revelou-se, também, adequada (VEM $\geq 0.5$ ), de acordo com a Tabela I.

\section{Tabela I}

Pesos fatoriais estandardizados dos itens $(\lambda)$, confiabilidade compósita (FC) e variância extraída média (VEM) do fator Liderança Autêntica

\begin{tabular}{|c|c|c|c|c|c|}
\hline Fator & Item & Questão & $\lambda$ & FC & VEM \\
\hline \multirow{5}{*}{$\begin{array}{l}\text { Transparência } \\
\text { Relacional }\end{array}$} & LAC1 & Diz exatamente o que pensa. & 0,848 & \multirow{5}{*}{0.950} & \multirow{5}{*}{0.796} \\
\hline & LAC2 & Assume os erros que comete. & 0,804 & & \\
\hline & LAC3 & Encoraja todos a dizer o que pensam. & 0,823 & & \\
\hline & LAC4 & Diz as duras verdades. & 0,830 & & \\
\hline & LAC5 & $\begin{array}{l}\text { Mostra as emoções que correspondem ao } \\
\text { que sentem. }\end{array}$ & 0,804 & & \\
\hline \multirow{4}{*}{$\begin{array}{l}\text { Perspetiva Moral } \\
\text { Integrada }\end{array}$} & LAC6 & $\begin{array}{l}\text { Demonstra que as suas ações são } \\
\text { consistentes com as suas crenças. }\end{array}$ & 0,844 & \multirow{4}{*}{0.916} & \multirow{4}{*}{0.731} \\
\hline & LAC7 & $\begin{array}{l}\text { Toma decisões baseado(a) nos seus } \\
\text { valores fundamentais. }\end{array}$ & 0,712 & & \\
\hline & LAC8 & $\begin{array}{l}\text { Pede-me para tomar posições de acordo } \\
\text { com os meus valores essenciais. }\end{array}$ & 0,743 & & \\
\hline & LAC9 & $\begin{array}{l}\text { Toma decisões difíceis baseado(a) em } \\
\text { elevados padrões éticos. }\end{array}$ & 0,810 & & \\
\hline \multirow{3}{*}{$\begin{array}{l}\text { Processamento } \\
\text { Equilibrado } \\
\text { Informação }\end{array}$} & LAC10 & $\begin{array}{l}\text { Solicita-me pontos de vista } \\
\text { questionem as suas posições mais } \\
\text { profundas. }\end{array}$ & 0,525 & \multirow{3}{*}{0.859} & \multirow{3}{*}{0.679} \\
\hline & LAC11 & $\begin{array}{l}\text { Analisa informação relevante antes de } \\
\text { tomar a decisão. }\end{array}$ & 0,816 & & \\
\hline & LAC12 & $\begin{array}{l}\text { Ouve cuidadosamente os diferentes } \\
\text { pontos de vista antes de tirar conclusões. }\end{array}$ & 0,862 & & \\
\hline \multirow{4}{*}{ Autoconsciência } & LAC13 & $\begin{array}{l}\text { Procura obter informação (feedback) das } \\
\text { pessoas para melhorar as interações com } \\
\text { elas. }\end{array}$ & 0,836 & \multirow{4}{*}{0.947} & \multirow{4}{*}{0.805} \\
\hline & LAC14 & $\begin{array}{l}\text { Tem uma noção clara do modo como os } \\
\text { outros encaram as suas (dele/a) } \\
\text { capacidades. }\end{array}$ & 0,797 & & \\
\hline & $\mathrm{LAC} 15$ & $\begin{array}{l}\text { Sabe quando é o momento de reavaliar as } \\
\text { suas posições em assuntos importantes. }\end{array}$ & 0,864 & & \\
\hline & LAC16 & $\begin{array}{l}\text { Mostra que compreende como as suas } \\
\text { ações têm impacto nos outros. }\end{array}$ & 0,866 & & \\
\hline
\end{tabular}




\section{Fernanda Nogueira, Carla Marques, Ana Sabino, Ivo Oliveira, Carlos Rouco e Ana Branca Carvalho}

A Tabela II apresenta as correlações entre os vários fatores da liderança autêntica.

Tabela II

Correlações entre os fatores

\begin{tabular}{|c|c|c|c|c|}
\hline & & Correlação (r) & $\mathbf{r}^{2}$ & $\bar{p}$ \\
\hline Transparência Relacional & Perspetiva Moral Integrada & 0.935 & 0.874 & **** \\
\hline Perspetiva Moral Integrada & $\begin{array}{l}\text { Processamento } \quad \text { Equil. } \\
\text { Informação }\end{array}$ & 0.925 & 0.856 & $* * *$ \\
\hline $\begin{array}{l}\text { Processamento Equilibrado } \\
\text { Informação }\end{array}$ & Autoconsciência & 0.884 & 0.781 & $* * *$ \\
\hline Perspetiva Moral Integrada & Autoconsciência & 0.903 & 0.815 & $* * *$ \\
\hline Transparência Relacional & $\begin{array}{l}\text { Processamento } \\
\text { Informação }\end{array}$ & 0.868 & 0.753 & $* * *$ \\
\hline Transparência Relacional & Autoconsciência & 0.913 & 0.834 & *** \\
\hline
\end{tabular}

$* * * \mathrm{p} \leq 0.001$

O quadrado da correlação entre os fatores é superior ao seu valor de VEM pelo que a validade discriminante dos fatores foi avaliada pelo teste de diferença do $\chi 2$ entre o modelo com correlação entre fatores fixa em 1 $(\chi 2 \mathrm{r})$ e o modelo não restrito $(\chi 2 \mathrm{u})$. Este teste revelou-se significativo para todas as relações assumindo um nível de significância de 0.01 , podendo afirmar-se a existência de validade discriminante entre os fatores. Assim, fica confirmada a validade e fiabilidade dos fatores que constituem o instrumento de medida "Liderança Autêntica".

\subsection{Capital Psicológico}

O modelo fatorial do PsyCap original, ajustado a uma amostra de 168 colaboradores, revelou uma qualidade de ajustamento sofrível $(\chi 2 / \mathrm{gl}=2.429 ; \quad \mathrm{CFI}=0.813 ; \quad \mathrm{GFI}=0.770 ; \quad \mathrm{PCFI}=0.724 ; \quad$ PGFI $=0.632 ;$ RMSEA $=0.093 ; \mathrm{P}[\mathrm{rmsea} \leq 0.05]=0.000$ ). Depois de eliminadas quatro observações outliers; removidos os itens Psy1 (Sinto-me confiante quando procuro uma solução para um problema de longo prazo), Psy3 (Quando tenho uma contrariedade no trabalho, tenho dificuldade em recuperar e seguir em frente), Psy8 (Sei que se algo de mal me pode acontecer no trabalho, isso acontecer-me-á), Psy20 (No trabalho, as coisas nunca me correm como eu gostaria) e Psy19 (Consigo ultrapassar os momentos difíceis no trabalho, pois já passei anteriormente por dificuldades) com pesos fatoriais inferiores a 0.5 ; removidos do modelo os itens Psy 13 (Sinto-me capaz de ajudar a definir objetivos para a minha área de trabalho), Psy17 (Sinto-me confiante quando estabeleço contato com pessoas fora da empresa (por exemplo, clientes e fornecedores) para 
discutir problemas) e Psy23 (Sinto que consigo lidar com muitas coisas ao mesmo tempo no trabalho), cujos índices de modificação sugeriam a saturação desses itens em fatores diferentes daqueles sugeridos na versão original. Correlacionados os erros de medida dos itens Psy4 (Quando as coisas estão incertas para mim no trabalho, habitualmente espero o melhor) e Psy24 (No meu trabalho, considero que todos os problemas têm um lado positivo) pertencentes ao fator Otimismo, foi possível obter uma qualidade de ajustamento muito boa $(\chi 2 / \mathrm{gl}=1.570 ; \quad \mathrm{CFI}=0.955$; GFI $=0.899 ; \quad$ PCFI $=0.772 ; \quad$ PGFI $=0.641 ; \quad$ RMSEA $=0.059$; $\mathrm{P}[\mathrm{rmsea} \leq 0.05]=0.197 ; \quad \mathrm{MECVI}=1.469)$. Adicionalmente, o modelo simplificado apresentou uma qualidade de ajustamento, significativamente superior à do modelo original na amostra em estudo $(\chi 2(97)=152.285$ vs. $\chi 2(224)=937.035)$, bem como um MECVI consideravelmente menor (1.469 vs. 4.328). A fiabilidade compósita dos fatores revelou-se elevada pelo que a fiabilidade do construto é adequada ( $\mathrm{FC} \geq 0.7)$. A variância extraída média (VEM), um indicador da validade convergente dos fatores, revelou-se, também, adequada (VEM $\geq 0.5$ ). A Tabela III apresenta os valores dos pesos fatoriais estandardizados, a fiabilidade compósita (FC) e a variância extraída média (VEM) do fator PsyCap no modelo final simplificado.

\section{Tabela III}

Pesos fatoriais estandardizados dos itens $(\lambda)$, confiabilidade compósita (FC) e variância extraída média (VEM) do fator "PsyCap"

\begin{tabular}{|c|c|c|c|c|c|}
\hline Fator & Item & Questão & $\lambda$ & FC & VEM \\
\hline \multirow{3}{*}{$\begin{array}{l}\text { Auto- } \\
\text { Eficácia }\end{array}$} & Psy5 & $\begin{array}{l}\text { Sinto-me confiante quando represento a } \\
\text { minha área de trabalho em reuniões com } \\
\text { a gestão de topo da organização. }\end{array}$ & 0,787 & \multirow{3}{*}{0.894} & \multirow{3}{*}{0.739} \\
\hline & Psy9 & $\begin{array}{l}\text { Sinto-me confiante quando participo em } \\
\text { discussões sobre a estratégia da } \\
\text { organização. }\end{array}$ & 0,831 & & \\
\hline & Psy21 & $\begin{array}{l}\text { Sinto-me confiante a apresentar } \\
\text { informação a um grupo de colegas. }\end{array}$ & 0,731 & & \\
\hline \multirow{4}{*}{ Otimismo } & Psy4 & $\begin{array}{l}\text { Quando as coisas estão incertas para } \\
\text { mim no trabalho, habitualmente espero } \\
\text { o melhor. }\end{array}$ & 0,575 & \multirow{4}{*}{0.863} & \multirow{4}{*}{0.617} \\
\hline & Psy 12 & $\begin{array}{l}\text { No que respeita ao meu trabalho, olho } \\
\text { sempre para o lado positivo das coisas. }\end{array}$ & 0,787 & & \\
\hline & Psy 16 & $\begin{array}{l}\text { No que diz respeito ao meu trabalho, } \\
\text { sou otimista acerca do que me } \\
\text { acontecerá no futuro. }\end{array}$ & 0,831 & & \\
\hline & Psy24 & $\begin{array}{l}\text { No meu trabalho, considero que todos os } \\
\text { problemas têm um lado positivo. }\end{array}$ & 0,581 & & \\
\hline
\end{tabular}




\begin{tabular}{|c|c|c|c|c|c|}
\hline \multirow{6}{*}{ Esperança } & Psy2 & $\begin{array}{l}\text { Se me encontro em uma situação difícil } \\
\text { no trabalho, consigo pensar em muitas } \\
\text { formas de sair dela. }\end{array}$ & 0,739 & \multirow{6}{*}{0.915} & \multirow{6}{*}{0.643} \\
\hline & Psy6 & $\begin{array}{l}\text { Atualmente, procuro alcançar os meus } \\
\text { objectivos com toda a energia. }\end{array}$ & 0,638 & & \\
\hline & Psy 10 & $\begin{array}{l}\text { Considero que, para qualquer problema, } \\
\text { existem muitas formas de resolvê-lo. }\end{array}$ & 0,671 & & \\
\hline & Psy 14 & $\begin{array}{l}\text { Neste momento, vejo-me como uma } \\
\text { pessoa bem sucedida no trabalho. }\end{array}$ & 0,783 & & \\
\hline & Psy 18 & $\begin{array}{l}\text { Consigo pensar em muitas formas de } \\
\text { alcançar os meus objetivos no trabalho. }\end{array}$ & 0,745 & & \\
\hline & Psy22 & $\begin{array}{l}\text { Neste momento, estou a alcançar os } \\
\text { objetivos profissionais que defini para } \\
\text { mim próprio(a). }\end{array}$ & 0,714 & & \\
\hline \multirow{3}{*}{ Resiliência } & Psy7 & $\begin{array}{l}\text { De um modo ou de outro, em geral } \\
\text { consigo gerir bem as dificuldades no } \\
\text { trabalho. }\end{array}$ & 0,577 & \multirow{3}{*}{0.815} & \multirow{3}{*}{0.598} \\
\hline & Psy 11 & $\begin{array}{l}\text { No trabalho, se for necessário, sou capaz } \\
\text { de ficar "por minha conta e risco". }\end{array}$ & 0,699 & & \\
\hline & Psy15 & $\begin{array}{l}\text { Em geral, ultrapasso com facilidade as } \\
\text { coisas mais stressantes no trabalho. }\end{array}$ & 0,772 & & \\
\hline
\end{tabular}

A validade discriminante dos fatores foi avaliada pela comparação das VEM com os quadrados da correlação entre fatores. A Tabela IV apresenta as correlações entre os vários fatores do PsyCap.

\section{Tabela IV}

Correlações entre os vários fatores

\begin{tabular}{|c|c|c|c|c|}
\hline & & $\begin{array}{c}\text { Correlação } \\
(\mathbf{r})\end{array}$ & $\mathbf{r}^{2}$ & $\mathbf{p}$ \\
\hline $\begin{array}{l}\text { Auto- } \\
\text { eficácia }\end{array}$ & Otimismo & 0.486 & 0.236 & $* * *$ \\
\hline Otimismo & Esperança & 0.845 & 0.714 & $* * *$ \\
\hline Esperança & Resiliência & 0.825 & 0.681 & $* * *$ \\
\hline Otimismo & Resiliência & 0.816 & 0.666 & $* * *$ \\
\hline $\begin{array}{l}\text { Auto- } \\
\text { eficácia }\end{array}$ & Esperança & 0.749 & 0.561 & $* * *$ \\
\hline $\begin{array}{l}\text { Auto- } \\
\text { eficácia }\end{array}$ & Resiliência & 0.637 & 0.406 & $* * *$ \\
\hline
\end{tabular}

O quadrado da correlação entre os fatores é inferior ao valor de VEM dos respectivos fatores para as correlações entre os fatores Autoeficácia e Otimismo, Autoeficácia e Esperança e, ainda, para a Autoeficácia com a Resiliência. No entanto, para os restantes 3 pares de correlações o 
quadrado da correlação entre os fatores é superior ao seu valor de VEM pelo que a validade discriminante dos fatores foi avaliada pelo teste de diferença do $\chi^{2}$ entre o modelo com correlação entre fatores fixos em 1 $(\chi 2 r)$ e o modelo não restrito $(\chi 2 u)$. Este teste revelou-se significativo para todas as relações, com um nível de significância de 0.001 , podendo afirmar-se a existência da validade discriminante entre os fatores, sendo confirmadas a validade e a fiabilidade dos fatores que constituem o instrumento de medida do PsyCap.

\subsection{Criatividade}

O modelo unifatorial da criatividade original composto por 13 itens.

$\mathrm{O}$ ajustamento à amostra de 168 colaboradores revelou uma boa qualidade $\quad(\chi 2 / \mathrm{gl}=1.663 ; \quad \mathrm{CFI}=0.978 ; \quad \mathrm{GFI}=0.909 ; \quad \mathrm{PCFI}=0.815$; PGFI=0.649; RMSEA=0.063; P[rmsea $\leq 0.05]=0.150$; MECVI=0.987). No entanto, a variável Cria13 (Este colaborador sugere novas formas de desempenhar as tarefas de trabalho) foi retirada do modelo por apresentar um peso fatorial de -0.014 , ao contrário dos restantes, que apresentaram pesos fatoriais elevados $(\lambda \geq 0.5)$. $\mathrm{O}$ modelo simplificado apresentou uma ligeira melhoria $(/ \mathrm{gl}=1.649 ; \quad \mathrm{CFI}=0.982 ; \quad \mathrm{GFI}=0.920 ; \quad \mathrm{PCFI}=0.804$; PGFI $=0.637$; RMSEA $=0.062 ; \mathrm{P}[\mathrm{rmsea} \leq 0.05]=0.183 ; \mathrm{MECVI}=0.845) \mathrm{em}$ relação ao original. A confiabilidade compósita do fator criatividade é de $0,981$ pelo que a fiabilidade do construto é adequada ( $\mathrm{FC} \geq 0.7)$.

\section{Tabela V}

Pesos fatoriais estandardizados dos itens $(\lambda)$, confiabilidade compósita (FC) e variância extraída média (VEM) do fator Criatividade

\begin{tabular}{|c|c|c|c|c|c|}
\hline Fator & Item & Questão & $\lambda$ & FC & VEM \\
\hline \multirow{7}{*}{ 宽 } & Cria1 & $\begin{array}{l}\text { Este colaborador sugere novas formas de } \\
\text { alcançar metas e objetivos. }\end{array}$ & 0,851 & \multirow{7}{*}{0,981} & \multirow{7}{*}{0.809} \\
\hline & Cria2 & $\begin{array}{l}\text { Este colaborador apresenta ideias novas e } \\
\text { práticas para melhorar a performance. }\end{array}$ & 0,877 & & \\
\hline & Cria3 & $\begin{array}{l}\text { Este colaborador procura novas tecnologias, } \\
\text { processos, técnicas e/ou ideias para produtos. }\end{array}$ & 0,826 & & \\
\hline & Cria4 & $\begin{array}{l}\text { Este colaborador sugere novas formas de } \\
\text { melhorar a qualidade. }\end{array}$ & 0,852 & & \\
\hline & Cria5 & $\begin{array}{l}\text { Este colaborador é uma boa fonte de ideias } \\
\text { criativas. }\end{array}$ & 0,872 & & \\
\hline & Cria6 & $\begin{array}{l}\text { Este colaborador não tem medo de correr } \\
\text { riscos. }\end{array}$ & 0,687 & & \\
\hline & Cria7 & $\begin{array}{l}\text { Este colaborador promove e apoia as ideias dos } \\
\text { outros. }\end{array}$ & 0,722 & & \\
\hline
\end{tabular}


Fernanda Nogueira, Carla Marques, Ana Sabino, Ivo Oliveira, Carlos Rouco e Ana Branca Carvalho

\begin{tabular}{|l|l|l|l|}
\hline Cria8 & $\begin{array}{l}\text { Este colaborador exibe criatividade no trabalho } \\
\text { quando lhe é dada oportunidade }\end{array}$ \\
\hline Cria9 & $\begin{array}{l}\text { Este colaborador desenvolve planos e } \\
\text { programas adequados para implementação de } \\
\text { novas ideias. }\end{array}$ & 0,813 \\
\hline Cria10 & $\begin{array}{l}\text { Este colaborador tem ideias novas e } \\
\text { inovadoras. }\end{array}$ & $\begin{array}{l}\text { Este colaborador surge com ideias novas e } \\
\text { criativas. }\end{array}$ \\
\hline Cria12 & $\begin{array}{l}\text { Este colaborador tem abordagens novas para os } \\
\text { problemas. }\end{array}$ & 0,908 \\
\hline
\end{tabular}

A variância extraída média (VEM), indicador da validade convergente dos fatores, de 0.809 (VEM $\geq 0.5)$, revelou-se adequada. Os itens que apresentaram maior peso fatorial foram o Cria11 (Este colaborador surge com ideias novas e criativas) e o Cria10 (Este colaborador tem ideias novas e inovadoras) e o de menor peso fatorial foi o Cria 6 (Este colaborador não tem medo de correr riscos). Validadas as escalas de medida através das AFCs para os fatores do modelo, foram calculados os seus scores que, posteriormente, foram utilizados na análise do modelo.

\section{RESULTADOS DAS EQUAÇÕES ESTRUTRURAIS}

O modelo de equações estruturais foi organizado em dois submodelos: (1) o de medida (correspondente a uma análise fatorial confirmatória), que define a forma como os constructos hipotéticos ou variáveis latentes são operacionalizados pelas variáveis observadas ou manifestas, e (2) o estrutural, que define as relações causais ou de associação entre as variáveis latentes. O submodelo causal foi avaliado em duas etapas, usando o método de estimação da máxima verosimilhança (Maroco, 2010). Numa primeira etapa foi aferida a qualidade de ajustamento do submodelo de medida e numa segunda etapa a qualidade de ajustamento do modelo causal. Estas etapas foram concretizadas de acordo com os índices de qualidade de ajustamento e respectivos valores de referência, a saber: $\chi 2 / \mathrm{gl}, \mathrm{CFI}, \mathrm{GFI}, \mathrm{RMSEA}, \mathrm{P}[\mathrm{rmsea} \leq 0.05]$ e MECVI (Maroco, 2010). A qualidade do ajustamento local foi avaliada pelos pesos fatoriais e pela confiabilidade individual dos itens. A significância das trajetórias causais foi avaliada com um teste $\mathrm{Z}$ aos rácios críticos. Consideraram-se significativas as trajetórias com $\mathrm{p}<0.05$. 


\section{$1^{\text {a }}$ etapa - Submodelo de Medida:}

O modelo mediado em estudo ajustado a uma amostra de 163 colaboradores revelou boa qualidade de ajustamento $(\chi 2 / \mathrm{gl}=1.489$; CFI $=0.980 ; \quad$ GFI $=0.876 ; \quad$ RMSEA $=0.054 ; \quad$ MECVI $=2,078$; $\mathrm{P}[\mathrm{rmsea} \leq 0.05]=0.307)$. Na Figura II encontram-se representados os valores dos pesos fatoriais estandardizados e a confiabilidade individual de cada um dos itens no submodelo de medida.

\section{Figura II}

Submodelo de medida

Submodelo de medida $\times 2(167)=248,590 ; p=, 000 ; \times 2 d f=1,489$

$\mathrm{CFI}=, 980 ; \mathrm{GFI}=, 876 ; \mathrm{MECVI}=2,078$

RMSEA $=, 054 ; \mathrm{P}($ rmsea $<=0.05)=, 307$

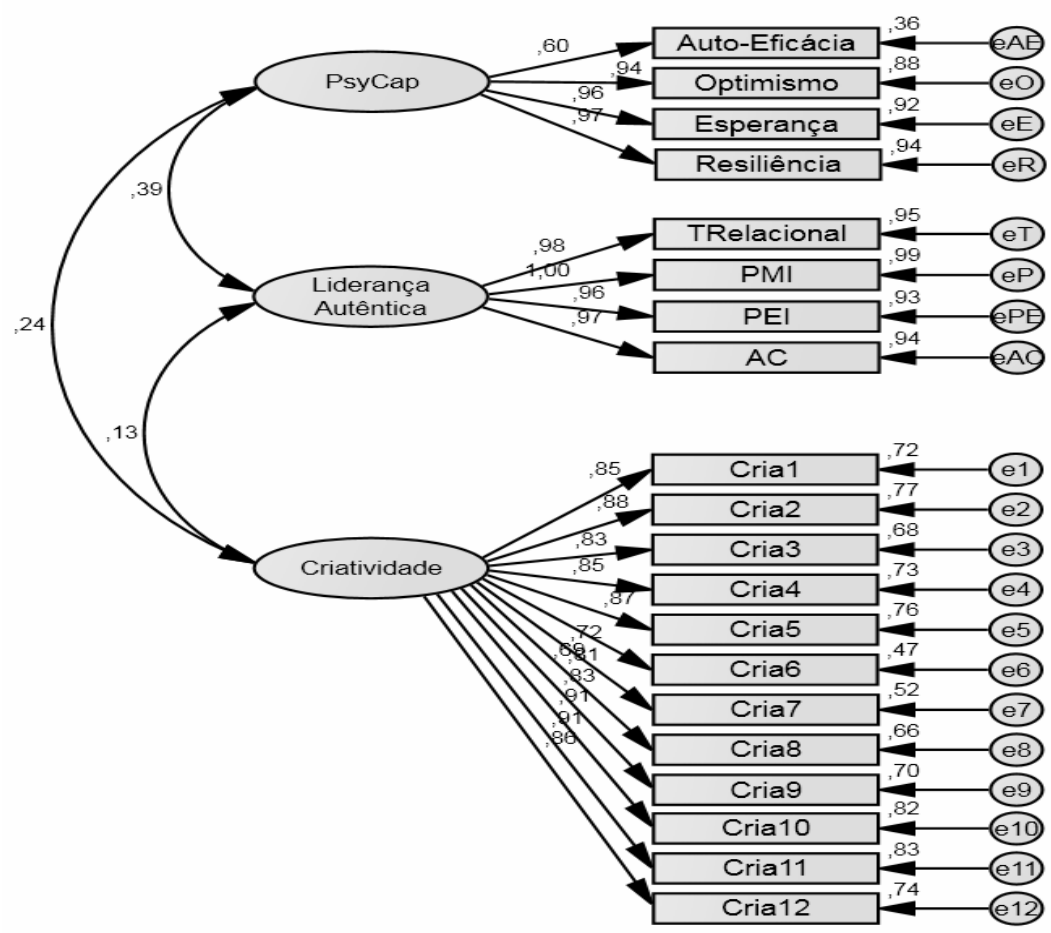

\section{$2^{\mathrm{a}}$ etapa - Submodelo Causal:}

A análise das trajetórias entre os fatores revelou que a trajetória Liderança Autêntica $\rightarrow$ PsyCap é a que apresenta maior peso 


\section{Fernanda Nogueira, Carla Marques, Ana Sabino, Ivo Oliveira, Carlos Rouco e Ana Branca Carvalho}

( $\beta$ Psy.LA $=0.395 ; \mathrm{p} \leq 0.001$ ), seguida da trajetória PsyCap $\rightarrow$ Criatividade $(\beta C$ Cri.Psy=0.228; $\mathrm{p}=0.010)$. Finalmente, a liderança autêntica tem um efeito direto por intermédio da trajetória Liderança Autêntica $\rightarrow$ Criatividade, a qual se revelou não significativa ( $\beta$ Cri.LA $=0,036$; $\mathrm{p}=0.664)$ e um efeito indireto por meio do PsyCap ( $\beta$ Cri.LA $\mid \mathrm{Psy}=0.036$; $\mathrm{p}=0.014$ ). O modelo em estudo, Figura III, apresenta os valores dos pesos fatoriais estandardizados no modelo final simplificado.

\section{Figura III}

Submodelo causal Modelo Causal $X 2(167)=248,590 ; p=, 000 ; x 2 d f=1,489$ $\mathrm{CFI}=, 980 ; \mathrm{GFI}=, 876 ; \mathrm{MECV}=2,078$ RMSEA $=, 054 ; P($ rmsea $<=0.05)=, 307$

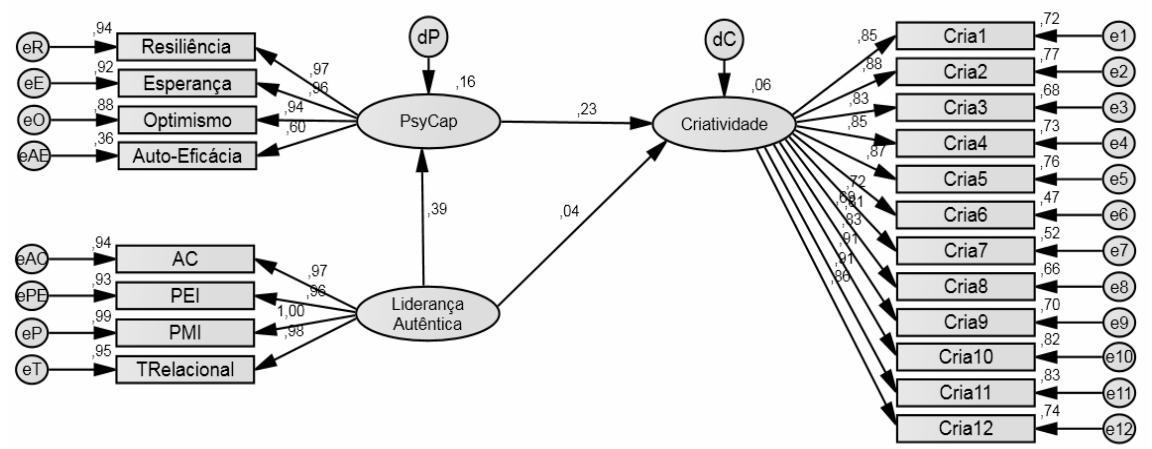

Pode concluir-se que os resultados estatísticos confirmam H1, H2 e não confirmam $\mathrm{H} 3$. O modelo apresenta a relação da liderança autêntica com o PsyCap e este com a Criatividade. A Liderança Autêntica não explica diretamente a Criatividade, figura 4.

\section{Figura IV}

Resultado das hipóteses de investigação

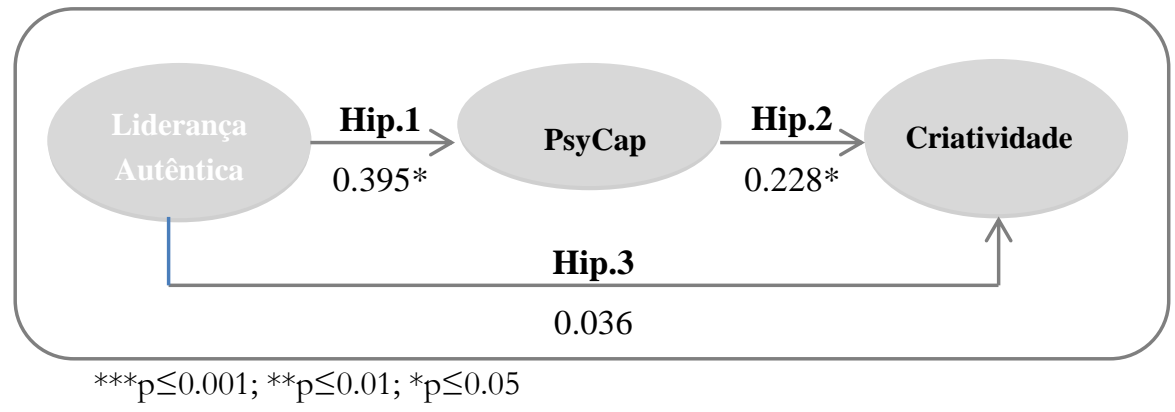




\section{DISCUSSÃO DOS RESULTADOS}

Os resultados encontrados corroboram alguns dos estudos acima apresentados, nomeadamente os realizados por Sousa (2009) em empresas comerciais de grande distribuição e por Vitória (2010) que abordou a liderança autêntica, as emoções positivas e o empenho, em colaboradores não docentes de uma Universidade Portuguesa. O modelo deste estudo, compreendendo líderes e colaboradores de organizações de saúde revelouse ajustado à amostra de um universo diferente ao dos autores anteriores. Ressalta-se que nesta pesquisa não foi estabelecida a relação direta entre a liderança e a criatividade dos colaboradores o que contraria estudos como os de George (2003), Avolio et al. (2004), Luthans et al. (2003), Walumbwa et al. (2005), entre outros.

Os resultados obtidos permitem ainda afirmar a existência de uma relação direta entre liderança e capital psicológico, comprovando-se a Hipótese 1, na qual a percepção da existência de liderança influencia positivamente o capital psicológico dos profissionais. Isto confirma que líderes autênticos fomentam a autenticidade nos seus seguidores e que a liderança autêntica e o capital psicológico causam um impacto no desempenho da organização, o que vai ao encontro dos trabalhos de Luthans e Avolio (2003), Mayer e Gavin (2005) e Gardner et al. (2005). Dessa forma, é possível dizer que líderes autênticos com níveis elevados de capital psicológico fomentam a confiança nos seus seguidores, proporcionando um ambiente de trabalho que se reflete positivamente no desempenho e na criatividade dos mesmos.

No que diz respeito à Hipótese 2, ou seja, "A percepção da existência de capital psicológico influencia positivamente o comportamento criativo dos profissionais", pode afirmar-se que existe uma relação direta entre estas duas variáveis, corroborando com outros estudos já anteriormente referidos. Os resultados sugerem, assim, que colaboradores mais criativos têm níveis de capital psicológico mais elevados, isto é: autoeficácia, otimismo, esperança, e resiliência (Luthans, Youssef \& Avolio, 2007). O capital psicológico pode, desta forma, ser visto como uma alavanca para a vantagem competitiva das organizações de saúde.

No que concerne à Hipótese 3, "A percepção da existência de liderança autêntica influencia positivamente o comportamento criativo dos colaboradores", verifica-se que não existe uma relação direta entre estas duas variáveis, o que contraria alguns dos estudos aqui já referidos. 


\section{Fernanda Nogueira, Carla Marques, Ana Sabino, Ivo Oliveira, Carlos Rouco e Ana Branca Carvalho}

Concluindo, pode dizer-se que os líderes autênticos apresentam elevados níveis de capital psicológico e possuem a capacidade de elevar os níveis de capital psicológico nos seus seguidores desenvolvendo, por meio de interações e relacionamentos autênticos, forças psicológicas (autoeficácia, esperança, otimismo, resiliência) que capacitam os seguidores a prosperar e a florescer com um impacto positivo na criatividade e no despenho organizacional (Kernis, 2003; Avolio et al, 2004; Avolio \& Gardner, 2005). Construir relacionamentos, apoiar mudanças, fortalecer equipes multidisciplinares e promover $\mathrm{o}$ autodesenvolvimento são habilidades fundamentais às lideranças que pretendam o desenvolvimento organizacional.

\section{CONCLUSÕES, IMPLICAÇÕES PARA A GESTÃO E SUGESTÕES PARA INVESTIGAÇÕES FUTURAS}

Consultando o documento emitido pelo Grupo Técnico para a Reforma da Organização Interna dos Hospitais $^{8}$, verifica-se que o modelo organizacional dos hospitais em Portugal, onde é reconhecível, não difere substancialmente do modelo do pós-guerra que o inspirou. Desta forma, a cultura de gestão que era esperado que evoluísse para modelos organizacionais, em si mesmos, capazes de gerar novas dinâmicas de gestão, não aconteceu, persistindo a indefinição estratégica, o planeamento incipiente ou inexistente, a falta de transparência nos processos de decisão, concorrendo para a desresponsabilização e para a ausência do desenvolvimento organizacional hospitalar (Ministério da Saúde, 2010). Ao lermos este diagnóstico e estando as organizações hospitalares interessadas em responder aos desafios atuais, a promoção de ambientes saudáveis, capazes de envolver os colaboradores e despertar a criatividade e a inovação, deixa de ser uma opção e passa a ser um caminho necessário para a concretização de projetos e missões. Para tal, deve edificar-se a confiança, promover a honestidade e a integridade e exigir altos padrões de ética no desenvolvimento das relações lídercolaborador.

Os resultados aqui obtidos, aplicados às organizações do sector da saúde, apresentam forte relação da liderança autêntica com o capital psicológico, indicando ser esta relação, tal com afirmam Walumbwa et al.

${ }^{8}$ http://www.spmi.pt/pdf/RelatorioFinalGTHospitaisVersaoFinal2.pdf consultado em 27 de dezembro de 2013. 
(2009), Crossan e Apaydin (2010) para outros sectores, uma alavanca do desenvolvimento organizacional. No entanto, não confirmamos a hipótese de a liderança autêntica influenciar diretamente a criatividade. $\mathrm{Na}$ tentativa de perceber a razão pela qual esta afirmação não foi comprovada, considera-se pertinente analisar fatores mais específicos das organizações hospitalares, aqui estudadas como por exemplo a fragmentação dos objectivos organizacionais. Estas organizações têm estabelecido, ao longo dos tempos, objetivos e metas com base nos vários departamentos que as compõem. A saber: metas para a gestão de topo, metas para as equipas médicas, metas para os serviços de enfermagem, metas para os vários serviços técnicos como se, cada um por si, fosse garante do sucesso da organização. O Instituto de Governança ${ }^{9}$ tem vindo a chamar à atenção para o facto das organizações hospitalares, com tanta departamentalização, objetivos e metas próprias e individualizadas, correrem o risco de não alcançarem o sucesso, no seu todo, e não garantirem o alcance dos objetivos e a sua própria sustentabilidade financeira. Os serviços comunitários, a conduta ética para com o doente e um atendimento de qualidade podem, também, ser postos em causa pela falta de uma estratégia única que tenha como centro de atuação o doente. Torna-se fundamental deixar de considerar as organizações de saúde como conglomerados de unidades e considerá-las como sistemas integrados, isso é, uma combinação integrada de processos, pessoas e outros recursos que, conjuntamente, poderão atingir o mesmo fim; tratar, cuidar do doente. Relembre-se que quer a classe profissional médica, com um significado determinante nestas organizações, através da sua atuação e poder de decisão, quer a colaboração direta de outras classes de profissionais, têm uma forte influência na obtenção dos objetivos e das metas organizacionais. Isso impede, possivelmente uma relação direta da liderança autêntica com o comportamento criativo dos colaboradores, fazendo destas organizações umas das mais complexas.

Para estudos futuros, sugerimos que sejam realizadas pesquisas sobre as várias lideranças, envolvendo as direções de topo destas organizações e

\footnotetext{
${ }^{9}$ Instituto de Governança fundado em 1986, nos Estados Unidos, reconhecido como a fonte mais proeminente de informação imparcial de governança, realiza estudos, acompanha tendências e revela práticas de governação em organizações de saúde. Fornece ferramentas, habilidades e experiencias que contribuam para melhorar a eficácia destas organizações. Leadership in Healthcare Organizations http://www.jointcommission.org/assets/1/18/WP_Leadership_Standards.pdf, consultado em 9 de Maio de 2012.
} 


\section{Fernanda Nogueira, Carla Marques, Ana Sabino, Ivo Oliveira, Carlos Rouco e Ana Branca Carvalho}

os corpos diretivos dos vários grupos profissionais. Tal envolvimento poderá vir a permitir não só o desenvolvimento deste constructo, como a identificação das suas relações com a cultura organizacional, o comportamento organizacional em torno dos macro-objectivos, as emoções de quem lidera e de quem é liderado, a confiança mútua, etc. Em suma, será urgente, num futuro próximo, conhecermos as dimensõeschave para a criatividade e o desenvolvimento organizacional hospitalar em torno do seu objectivo (ou mesmo recurso) central; o doente.

\section{BIBLIOGRAFIA}

Alencar, E.; Fleith, D. (2003). Contribuições Teóricas Recentes ao Estudo da Criatividade. Psicologia: Teoria e Pesquisa, v.19, n.1, p. 01-08.

Amabile, T. M. (1989). Growing up creativity. Buffalo. New York: The creativity Education Foundation Press.

Amabile, T. M. (1983). The social psychology of creativity. New York: Springer-Verlag.

Amabile, T. M. (1988). A model of creativity and innovation in organizations. In: Staw, B. M.; Cummings, L. L. (Eds.). Research in organization behaviour, v.10, Greenwich, CT: JAI Press.

Amabile, T. M. (1986). Creativity in context: Update to the social psychology of creativity. Boulder, CO: Westview Press.

Avolio, B. J.; Gardner, W. L.; Walumbwa, F. O.; Luthans, F.; May, D. R. (2004). Unlocking the mask: A look at the process by which authentic leaders impact follower attitudes and behaviours. Leadership Quarterly, n.15, p. 801-823.

Avolio, B. J.; Gardner, W. L. (2005). Authentic leadership development: Getting to the root of positive forms of leadership. The Leadership Quarterly, n.16, p. 315-338.

Avolio, B. J.; Luthans, F.; May, D.; Walumbwa, F. (2005). Can you see the real me? A self-based model of authentic leader and follower development. The Leadership Quarterly, n ${ }^{\circ}$ 16, p. 343-372.

Barañano, A. (2004). Métodos e técnicas de investigação em gestão. Lisboa: Sílano.

Blanchard, K. (2009). Um nível superior de liderança. Lisboa: Actual Editora.

Bunker, K.A.; Wakefield, M. (2005). Leading with authenticity in times of transition. Center for Creative Leadership. 
Carvalho, M. (2008). Gestão e Liderança na Saúde - uma abordagem estratégica. Porto: Editora Vida Económica.

Ceitil, M. (2006). Gestão de recursos humanos para o século XXI. Lisboa: Edições Sílabo.

Crossan, M. M.; Apaydin, M. (2010). A Multi-Dimensional Framework of Organizational Innovation: A Systematic Review of the Literature. Journal of Management Studies, v. 47, n.6.

Csikszentmihalyi, M. (1988). Society, culture, and person: a systems view of creativity. In Sternberg, R. J. (Eds.). The Nature of Creativity: 325339. New York: Cambridge University Press.

Csikszentmihalyi, M. (1996). Creativity. New York: Cambridge University Press.

Csikszentmihalyi, M. (2003). Good business: Leadership, flow, and making of meaning. New York: Penguin.

Cunha, M.; Rego, A. (2009). Liderar. Alfragide: Publicações Dom Quixote.

Cunha, M.; Rego, A.; Cunha, R. (2007). Organizações positivas. Lisboa: Publicações Dom Quixote.

Fredrickson, B.L. (2003). The value of positive emotions. American Scientist, v.91, p.330-335.

Frederico, M. (2006). Organizações, trabalho e carreira. Loures: Lusociência.

Fornell, C.; Larcker, D.F. (1981). Evaluating Structural Equation Models with Unobservable Variables and Measurement Error. Journal of Marketing Research, v.18, n. 1, p. 39-50.

Friedman, T.L. (2005). The world is flat. New York: Farrar, Straus, and Giroux.

Gardner, W.L.; Avolio, B.J.; Luthans, F.; May, D.R., Walumbwa, F. (2005). Can you see the real me? A selfbased model of authentic leader and follower development. Leadership Quarterly, v.16, p.343372.

George, B. (2009). Liderança autêntica: Resgata os valores fundamentais e construa organizações duradouras. São Paulo: Editora Gente.

George, B. (2003). Authentic leadership: Rediscovering the secrets to creating lasting value. San Francisco: CA7 Jossey-Bass.

George, J.M.; Zhou, J. (2007). Dual tunning in a supportive context: Joing contributes of positive mood, negative mood, and supervisory 


\section{Fernanda Nogueira, Carla Marques, Ana Sabino, Ivo Oliveira, Carlos Rouco e Ana Branca Carvalho}

behaviors to employee creativity. Academy of Management Journal, v.50, n.3, p.605-622.

Goleman, D.; Boyatzis, R.; McKee, A. (2002). Primal leadership: Realizing the power of emotional intelligence. Boston: Harvard Business School Press.

Goleman, D.; Boyatzis, R.; McKee, A. (2007). Os novos Líderes. Lisboa: Gradiva.

Graetz, F.; Smith, A. (2009). Duality theory and organizing forms in change management. Journal of Change Management, v.9, n.1). p.925.

Hooper, A.; Potter, J. (2010). Liderança inteligente - Criar a paixão pela mudança. Lisboa: Actual Editora.

House, D. (2003). The top five profit drains and how to plug them. Journal of Business Strategy, n.24, p. 32-35.

Ilies, R.; Morgeson, F. P. Nahrgang, J. D. (2005). Authentic leadership and eudaemonic well-being: Understanding leader-follower outcomes. The Leadership Quarterly, v. 16, p. 373-394.

James, K.; Brodersen, M.; Eisenberg, J. (2004). Workplace affect and workplace creativity: A review and preliminary model. Human Performance, v.17, n.2, p.169-194.

Kernis, M. H. (2003). Toward a conceptualization of optimal self-esteem. Psychological Inquiry, v.14, p.1-26.

Lakatos, E.; Marconi, M. (2007). Metodologia científica. São Paulo: Atlas.

Luthans, F.; Avolio, B. (2003). Authentic leadership: a positive development approach. In: K. S. Cameron, K.S.; Dutton, J.E; Quinn, R.E. (Eds.). Positive Organizational Scholarship, p.241-258, BerrettKoehler, San Francisco, CA.

Luthans, F. (2002a). Positive organizational behavior: Developing and managing psychological strengths. Academy of Management Executive, v.16, p. 57-72.

Luthans, F. (2002b). The need for and meaning of positive organizational behavior. Journal of Organizational Behavior, v.23, p.695-706.

Luthans, F.; Luthans, K.W.; Luthans, B. C. (2004). Positive psychological capital: Human and social capital. Business Horizons, v. 47, n. 1, p.4550.

Luthans, F.; Youssef, C.M. (2004). Human, Social and Now Positive Psychological Capital Management: Investing in People for 
Competitive Advantage. Organizational Dynamics, v.33, n.2, p.143160.

Luthans, F.; Youssef, C.M. (2007). Emerging positive organizational behavior. Journal of Management, v.33, p.321-349.

Luthans, F.; Youssef, C.M.; Avolio, B.J. (2007). Psychological Capital: Developing the human competitive edge. Oxford, UK: Oxford University Press.

Luthans, F.; Avolio, B.J.; Avey, J.B. et al. (2007). Positive psychological capital: Measurement and relationship with performance and satisfaction. Personnel Psychology, v.60, n. 3, p. 541-572.

Luthans, F.; Avey, J.B.; Avolio, B.J.; Norman, S.; Combs, G.M. (2006). Psychological capital development: toward a micro-intervention. Journal of Organizational Behavior, v.27, n.3, p. 387-393.

Lyubomirsky, S. (2008). The how of happiness: A scientific approach to getting the life you want. New York: Penguin Press,.

Maroco, J. (2010). Análise estatística com utilização do SPSS. $4^{\mathrm{a} E d i c ̧ a ̃ o . ~}$ Lisboa: Ed. Silabo.

May, R.; Chan, A.; Hodges, T.; Avolio, B. (2003). Developing the moral component of authentic leadership. Organizational Dynamics, v.32, p.247-260.

Mayer, J. D.; Gavin, M. B (2005). Trust in management and performance: Who minds the shop while the employees watch the boss? Academy of Management Journal, v.48, p.874-888.

Maxwell, J. (2010). As 21 indispensáveis qualidades de um líder. Lisboa: Smartbook.

Ministério da Saúde Portugal (2010). A Organização Interna e a Governação dos Hospitais. Disponível em http://www.spmi.pt/pdf/RelatorioFinalGTHospitaisVersaoFinal2.pdf. Consultado a 27 de dezembro de 2013.

Oldham, G.R.; Cummings, A. (1996). Employee creativity: Personal and contextual fators at work. Academy of Management Journal, v.39, p. 607-634.

Piderit, S.K. (2000). Rethinking resistance and recognizing ambivalence: A multidimensional view of attitudes toward an organizational change. Academy of Management Review, v.25, n.4, p.783-794.

Peterson, S. J.; Luthans, F. (2003). The positive impact and development of hopeful leaders. Leadership and Organizational Development Journal, v.24, p.26-31. 


\section{Fernanda Nogueira, Carla Marques, Ana Sabino, Ivo Oliveira, Carlos Rouco e Ana Branca Carvalho}

Rego, A; Cunha, M. (2010). Liderança positiva, $2^{\mathrm{a}}$ ed., Lisboa: Silabo.

Rego, A.; Sousa, F.; Cunha, M. P.; Correia, A.; Saur-Amaral, I. (2007). Leader selfreported emotional intelligence and perceived employee creativity: An exploratory study. Creativity and Innovation Management, v.16, n.3, p.250-264.

Rego, A.; Sousa, F.; Marques, C.; Cunha, M. (2012). Authentic leadership promotion employees' psychological capital and creativity. Journal of Business Research, v.65, n.3, p. 429-437.

Schyve, P. M. (2009). Leadership in healthcare organizations. A guide to joint commission leadership standards. The Governance Institute, San Diego.

Scott, S. G.; Bruce, R. A. (1994). Determinants of innovative behavior: A path model of individual innova-tion in the workplace. Academy of Management Journal, v.37, p.580-607.

Shalley, C. E.; Gibson, L. L. (2004). What leaders need to know: A review of social and contextual fators that can foster or hinder creativity. The Leadership Quarterly, v.15, n.1, p.33-53.

Shamir, B.; Eilam, G. (2005). What's your story? A life-stories approach to authentic leadership development. The Leadership Quarterly, v.16, p.395-417.

Sousa, M. F. N. (2009). Liderança Positiva e Criatividade dos Colaboradores. Tese (Doutoramento em Gestão) - Universidade de Trás-os-Montes e Alto Douro.

Sousa, F.; Monteiro I. (2010). Liderança de Equipas. Lisboa: Edições Sílabo.

Sternberg, R. J. (1988). A three-facet model of creativity. In: Sternberg, R. J. (Eds.). The Nature of creativity: Contemporary psychological perspective. Cambridge: Cambridge University Press. p. 125-147.

Sternberg, R.J.; Lubart, T.I. (1991). An investment theory of creativity and its development. Human Development, v.34, p.1-31.

Vitória, A.T. (2010). Liderança Positiva, Emoções Positiva, Empenhamento. Dissertação (Mestrado em Gestão) - Universidade de Aveiro.

Walumbwa, F.O.; Lawler, J.J.; Avolio, B.J.; Wang, P. Shi, K. (2005). Transformational leadership and work related attitudes. The moderating effects of collective and selfefficacy across cultures. Journal of Leadership and Organisational Studies, v.11, p.2-16. 
Walumbwa, F.O.; Wang, P.; Wang, H.; Schaubroeck, J. Avolio, B.J. (2010). Psychological process linking authentic leadership to follower behaviors. The Leadership Quarterly, v.21, n.5, p.901-914.

Walumbwa, F.O.; Avolio, B.J.; Gardner, W.L.; Wernsing, T.S.; Peterson, S.J. (2008). Authentic leadership: Development and validation of a theory-based measure. Journal of Management, v.34, n.1, p.89-126.

Walumbwa, F.O.; Luthans, F.; Avey, J.B.; Oke, A. (2009). Authentically leading groups: The mediating role of collective psychological capital and trust. Journal of Organizational Behavior, v.30, p.1-21.

Wang, A.; Cheng, B. (2010). When does benevolent leadership lead to creativity? The moderating role of creative role identity and job autonomy. Journal of Organizational Behavior, v.31, n.1, p.106-121.

Zhang, X.; Bartol, K. (2010). Linking empowering leadership and employee creativity: The influence if psychological empowerment, intrinsic motivation, and creative process engagement. Academy of Management Journal, v.53, n.1, p.107-128.

Zhou, J.; George, J. (2001). When job dissatisfaction leads to creativity: Encouraging the expression of voice. Academy of Management Journal, v.44, n.4, p.682-696.

Zhou, J.; George, J. (2003). Awakening employee creativity: The role of leader emotional intelligence. The Leadership Quarterly, v.14, p.545 568.

Zhou, J.; Shalley, C.E. (2003). Research on employee creativity: A critical review and directions for future research. In: Martocchio, J.J.; Ferris, G.R. (Eds.). Research in personnel and human resource management. Oxford: Elsevier Science, v.22, p.165-217.

Zhou, J.; Ren, R. (2012). The Oxford handbook of positive organizational scholarship. Oxford, UK: Oxford University Press, p.97-109. 